\title{
Developing Laboratory Performance Models for Thin Asphalt Overlay Mixtures
}

\author{
Mousa Zeki \\ Shakir Al-Busaltan \\ Department of Civil Engineering, University of Kerbala, Karbala, Iraq \\ mousazekitz@gmail.com_shakerfa2003@yahoo.com
}

\begin{tabular}{|l|l|l|}
\hline Submission date:- 17/2/2019 & Acceptance date:- 13/3/2019 & Publication date:-7/4/2019 \\
\hline
\end{tabular}

\begin{abstract}
Statistical modeling is utilized effectively to development relation/s between the dependent variables and independent variables. In other words, it describes how one or more random variables are related to one more other variables. Building verified models can help in predicting performance characteristics, and saving time and money. This study aims to present a statistical models which help to understand the significance of the different parameters in characterizing the performance of the Thin Asphalt Overlay (TAO). The experimental program included: design the thin asphalt overlay mixtures using one gradation type (9.5 Nominal Maximum Aggregate Size NMAS), three filler types (conventional mineral filler, Ordinary Portland Cement, and Quick lime), and five percentages of asphalt content to identify the optimum asphalt content. Then, Styrene Butadiene Styrene (SBS) modified polymer binder was introduced for performance enhancement. Performance tests were used to evaluate TAO mixture in term of some main namely, volumetric, mechanical, and durability properties are (bulk density, indirect tensile strength and tensile strength ratio). Statistical Product and Service Solutions (SPSS) software (Version 24) was used as a tool for models building. To find the most accurate statistical models, linear and nonlinear regression was achieved. This study demonstrates that the using statistical modeling is achievable and offer a vital tool to describe the characteristics and performance of the TAO mixture in term volumetric, mechanical and durability properties.
\end{abstract}

Keywords: Statistical model; Thin asphalt overlay; Polymer modified asphalt; Indirect tensile strength; Bulk density; Tensile strength ratio; Quicklime.

\section{Introduction}

Thin asphalt overlay (TAO) is a bituminous surface treatment layer that apply to enhances the current properties of pavement structure as far as it is strengthening pavement and eliminating the deformability [1]. TAO is generally the highest level of preventive maintenance treatment, which can perform on asphaltsurfaced pavements. The thickness of TAO is typically $38.1 \mathrm{~mm}$ or less, and TAO contained of finer aggregates with nominal maximum aggregate size of $12.5 \mathrm{~mm}$ or fewer. TAO provide for roads that need improvements for smoothness and safety an economical resurfacing and renewal paving solution [2]. Moreover, TAO is not only provided a new pavement surface for a fraction costly rebuilding roadway, but it is also the only preventive maintenance technique that simultaneously improves the structural value and extends the pavement's service life. Principally, this technique has been performed by many transportation agencies with varying success.

Volumetric, mechanical and durability properties are the important indexes for characterizing the TAO properties, which then use extensively to describe the variation produced TAOs. Standardized and nonStandardized testing methods, also empirical, simulative, and fundamental test methods, are all nominated to determine TAQs properties. Determining the asphalt mixtures resistance to the main paving distresses including low temperature cracking, fatigue cracking and rutting is the important role played by the properties of the TAO. Also this properties impact on asphalt mixture durability in term of aging and stripping [3], [4].

One of The main elements in the design of asphalt mixtures is the volumetric characteristics. In most cases, asphalt mixtures are considered in terms of weight proportion of bitumen and/or aggregate. However, for the design of asphalt mixtures, it is very important to consider the three main components in asphalt mixtures, namely bitumen, aggregate and air. Understanding the behavior of asphalt mixtures, whether in 
laboratory or in service, depends on the complex interaction between the three mentioned components. The asphalt mixture composition can be stated in terms of volume or weight. Since the air does not have a mass, if three components are taken into consideration, the asphalt mixture composition are expressed in terms of volume. For example, an asphalt mixture consists of $95 \%$ aggregate and $5 \%$ of bitumen by the total weight, will change when the asphalt mixture composition is take into account to be volumetrically. Probably the most important factor that has a significant impact on performance of asphalt pavement is the amount of voids in the mixture. Study was made by The National Cooperative Highway Research Program and state that the asphalt pavement resistance to rutting decrease with increase the voids in mineral aggregate (VMA) and asphalt content [5]. [6], [7] state that the high values of VMA can be guaranteed good durability however still achieving high value of rutting resistance. Density can be considered as one of the most significant criteria in the formation of asphalt mixtures. The amount of air voids in the asphalt mixture that has been designed is sufficient to prevent the occurrence of rutting and also low enough to prevent water and air permeability. Since density change through asphalt mixture life, therefor the voids should be sufficient to avoid plastic flow and should be low enough to avoid water and air permeability [8].

Asphalt mixes have attracted many researchers and engineers trying to improve their dynamic properties due to the growth in traffic volume, traffic loading and tire pressure, and harsh environments which have ultimately increased stresses on asphalt pavements [9]-[11] Huge traffic loading and harsh environments are two key parameters that affect mechanical and dynamic properties of asphalt mixture pavement. Early signs of cracks and deterioration were shown on the pavement as major consequences of these parameters. As a result of cracking problems, tensile properties are important characteristics of pavement engineers. The utilization of indirect tensile strength test (IDT) is to obtained tensile properties of asphalt mixture that related to the cracking properties of asphalt pavement [12], [13].

The premature failures of Asphalt Concrete Pavement have several reasons. Most of these reasons are related to environment conditions and/or traffic loads. Some of the environmental conditions such as water or moisture, temperature and air have detrimental effects on the pavement performance of asphalt pavement. However, water damage and ageing effect are normally characterized through specified testing to identify the potential of asphalt mixture to resist these long term or durable effects. The most environmental factors influencing the durability of asphalt mixture are the moisture induced damaged and the stripping of its components due to loss bitumen- aggregate adhesion [14]. Moisture damage represents the action of degradation of asphalt mixture strength and their durability due to presence of moisture or water, and may be evaluated by losing of mechanical properties of asphalt mixture. The phenomenon of moisture damage in asphalt mixture can generally be categorized in two mechanisms:(a) adhesion loss between asphalt binder and aggregate due to presence of water at aggregate-binder interface,(b) loss of cohesion of bitumen itself due to the softening action [15]. The amount and types of moisture damage are affected by several factors; some of these factors are associated with components of asphalt mixture such as bitumen and aggregate. Other factors are associated with the processes of design, production and construction of asphalt mixture.

Statistical model is a mathematical equation used to describe the relationship between variables. Statistical model shows how to relate one or more random variables to another variable. Statistical methods are used to improve the experimental methods, in which, instead of selecting one starting mix proportion and then adjusting by trial and error for achieving the optimum solution [16].

Predictive modeling can be defined as a set of mathematical techniques whose main objective is to establish a mathematical relationship between a dependent variable and different independent or predictive variables, taking into account measuring future values of those predictors and input them into the relationship to predict future values of the goal variable.

The overall aim of this study is to develop a predictive equations correlate the depended variable with independent variable where selected from mechanical, volumetric and durability properties (namely, IDT, TSR and bulk density) act as depended variables, whereas filler types like conventional mineral filler, ordinary Portland cement, quicklime and percent of SBS represent as independent variables. These models will help in understanding the characteristics of the produced TAO in one hand. While, in the other hand it can used as objective functions in optimization process. 


\section{Materials and methodology \\ 2.1 Raw material}

The aggregate used in this study were sieved, separated and graded in the lab to meet the specified gradation for surface course type III B (9.5 mm NMAS) according to General Specification for Roads and Bridges of Iraq [17]. Figure (1) show particle size distribution of the nominated aggregates gradation. However, the mid-range of the GSRB specification was specified to produce the tested gradation for TAO mixtures.

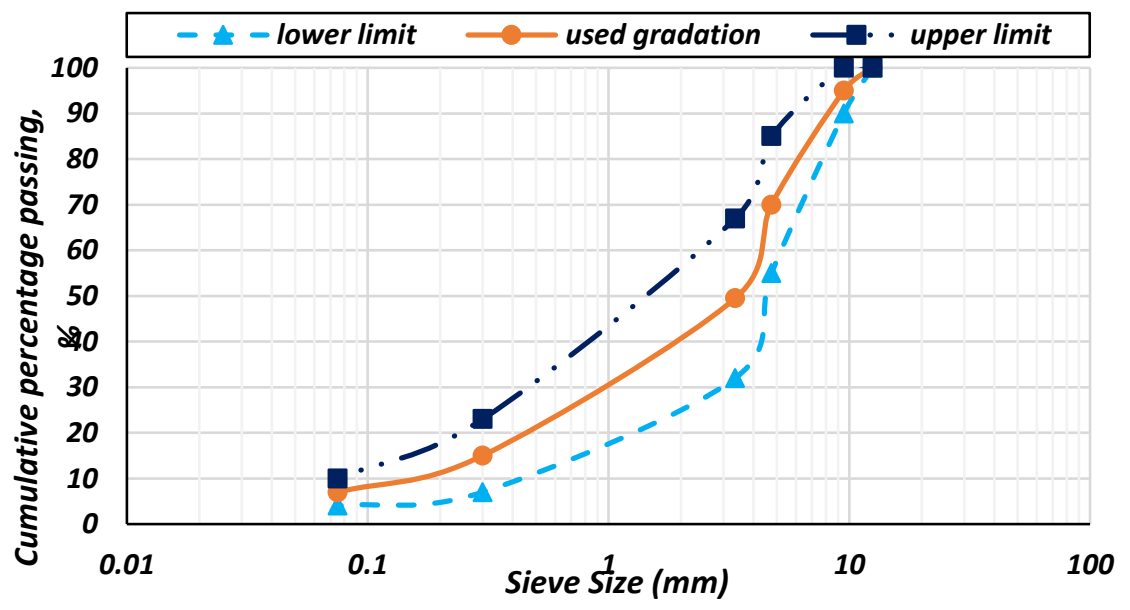

Figure 1 Distribute of Particle Size of the Used Gradation for Virgin aggregate (dense graded wearing course)

In this study, various filler types were used, namely, Quick lime (QL), Ordinary Portland Cement (OPC) and conventional mineral filler (CMF) to explore the potential of these fillers in achieving the mentioned purposes. The portion of crush aggregate and natural sand that passed from sieve NO. 200 was used as CMF filler, normally as it gained in asphalt plant. While the OPC and QL were provided from Karbala Cement Plant, and Karbala Lime Plant, respectively. Table (1) illustrates the physical and chemical properties of the used three type fillers.

\section{Table 1 the Utilized Fillers Properties}

\begin{tabular}{|c|c|c|c|}
\hline \multicolumn{4}{|c|}{ Physical Properties } \\
\hline \multirow[t]{2}{*}{ Property } & \multicolumn{3}{|c|}{ Filler type } \\
\hline & $C M F$ & $O P C$ & $Q L$ \\
\hline Specific surface area $\left(\mathrm{m}^{2} / \mathrm{kg}\right)$ & 225 & 410 & 3050 \\
\hline Density $\left(\mathrm{gm} / \mathrm{cm}^{3}\right)$ & 2.61 & 2.987 & 3.4 \\
\hline \multicolumn{4}{|c|}{ Chemical testing } \\
\hline $\mathrm{SiO} 2$ & 81.89 & 25.41 & 2 \\
\hline $\mathrm{Al2O3}$ & 3.78 & 2.324 & 1.35 \\
\hline $\mathrm{Fe} 2 \mathrm{O3}$ & 1.92 & 1.125 & 0.76 \\
\hline $\mathrm{CaO}$ & 7.37 & 65.148 & 85.5 \\
\hline $\mathrm{MgO}$ & 3.45 & 1.326 & 0.34 \\
\hline $\mathrm{K2O}$ & 0.73 & 0.760 & 0.3 \\
\hline $\mathrm{Na2O}$ & 0.19 & 1.714 & 0.12 \\
\hline
\end{tabular}

The asphalt binder that used in this study was supplied from AL-Daurah refinery with a grad of (4050). The properties of this asphalt were detailed in Table (2), whereas all the tests were carried out in the laboratories of University of Kerbala according to GSRB specification. 
Table 2 Grade Asphalt Cement Properties

\begin{tabular}{|c|c|c|c|}
\hline Property & ASTM designation & $\begin{array}{c}\text { Test } \\
\text { results }\end{array}$ & $\begin{array}{c}\text { GSRB } \\
\text { requirements }\end{array}$ \\
\hline $\begin{array}{l}\text { Penetration, } 100 \mathrm{gm} ., 25^{\circ} \mathrm{C}, 5 \mathrm{sec}(1 / 10 \\
\mathrm{mm})\end{array}$ & D5 [18] & 41 & $40-50$ \\
\hline Specific Gravity, $25^{\circ} \mathrm{C}(\mathrm{gm} / \mathrm{cm} 3)$ & D70 (ASTM, 2009a) & 1.03 & - \\
\hline Ductility, $25^{\circ} \mathrm{C}, 5 \mathrm{~cm} / \mathrm{min}(\mathrm{cm})$ & D113 [19] & 135 & $>100$ \\
\hline Flash point, $\left({ }^{\circ} \mathrm{C}\right)$ & D92 [20] & 313 & $>232$ \\
\hline Softening point $\left({ }^{\circ} \mathrm{C}\right)$ & D36 [21] & 47 & - \\
\hline Solubility in trichloroethylene, (\%) & D2042 [22] & 99.5 & $>99$ \\
\hline \multicolumn{4}{|c|}{ After Thin Film Oven test } \\
\hline Penetration of Residue (\%) & \multirow{2}{*}{ D 1754 [23] } & 69 & $>55$ \\
\hline Ductility of Residue, $(\mathrm{cm})$ & & 68.5 & $>25$ \\
\hline
\end{tabular}

The Styrene Butadiene Styrene (SBS) Kraton D1192 E (which is a copolymer consists of styrene and butadiene with $30 \%$ bound styrene) was nominated in this study with three percentages $(2,4$ and $6 \%)$. The properties of the modified SBS polymer and gradation are demonstrated in Tables ( 3 and 4), while the properties of the modified bitumen presented in Table (5).

Table 3 Kraton D1192 ESM polymer gradation

\begin{tabular}{|l|c|}
\hline Sieve size $(\mathrm{mm})$ & Passing\% \\
\hline NO.20 $(850 \mu \mathrm{m})$ & 100 \\
NO.30 $(600 \mu \mathrm{m})$ & 93.5 \\
NO.40 $(425 \mu \mathrm{m})$ & 69.5 \\
NO.50 $(300 \mu \mathrm{m})$ & 34.2 \\
NO.60 $(250 \mu \mathrm{m})$ & 15.7 \\
NO.80 $(180 \mu \mathrm{m})$ & 8 \\
NO.100 $(150 \mu \mathrm{m})$ & 3.8 \\
NO.200 $(75 \mu \mathrm{m})$ & 0 \\
\hline
\end{tabular}

Table 4 used polymer properties

\begin{tabular}{|l|l|l|c|l|}
\hline Property & Test Method & Unit & Tested Value & note \\
\hline Specific Gravity & SO 2781 & ----- & 0.94 & \\
\hline Melt Flow Rate, 200 ${ }^{\circ}$ C/5kg & ISO 1133 & $\mathrm{g} / 10 \mathrm{~min}$. & 1 & \\
\hline Bulk Density & $\begin{array}{l}\text { ASTM D 1895 } \\
\text { method B }\end{array}$ & $\mathrm{kg} / \mathrm{dm} 3$ & 0.4 & \\
\hline Hardness, Shore A (15 sec) & ASTM D 2240 & $\begin{array}{l}\text { Hardness, Shore } \\
\text { A }(15 \mathrm{sec})\end{array}$ & 70 & $\mathrm{a}$ \\
\hline $\begin{array}{l}\text { Apparent Molecular Mass of } \\
\text { Triblock }\end{array}$ & KM 01 & $\mathrm{kg} / \mathrm{mol}$. & 150 & \\
\hline Polystyrene Content & KM 03 & $\% \mathrm{~m}$ & 30.5 & \\
\hline Vinyl Content & KM 03 & $\%$ & 35 & \\
\hline Triblock Content & KM 01 & $\%$ & 90 & \\
\hline Total Extractable & KM 05 & $\% \mathrm{~m}$ & 1.0 & \\
\hline Volatile Matter & KM 04 & $\% \mathrm{~m}$ & 0.3 & \\
\hline Antioxidant Content & KM 08 & $\% \mathrm{~m}$ & 0.16 & \\
\hline Ash $($ ES, ET) & ISO 247 & $\% \mathrm{~m}$ & 0.25 & \\
\hline Ash $($ ETM $)$ & BAM 908 & $\% \mathrm{w}$ & 3 & \\
\hline Ash $($ ESM $)$ & ISO 247 & $\% \mathrm{~m}$ & 3.75 & \\
\hline
\end{tabular}


Journal of University of Babylon for Engineering Sciences, Vol. (27), No. (1): 2019.

a Measured-on compression molded slabs

Table 5 neat and modified bitumen properties

\begin{tabular}{|l|c|c|c|c|c|}
\hline \multicolumn{1}{|c|}{ Properties } & Standard (ASTM) & Osbs & $2 s b s$ & $4 s b s$ & $6 s b s$ \\
\hline Penetration at $25^{\circ} \mathrm{C}(0.1 \mathrm{~mm})$ & D5-73 & 40.7 & 27.2 & 23.5 & 22 \\
\hline Softening point $\left(R \& B{ }^{\circ} \mathrm{C}\right)$ & $\mathrm{C} 36-76$ & 48 & 59 & 62 & 64 \\
\hline Ductility at $25^{\circ} \mathrm{C}(\mathrm{cm})$ & D113-79 & $>100 \mathrm{~cm}$ & $>100 \mathrm{~cm}$ & 85 & 78 \\
\hline Penetration index & D5 & -2.1 & -0.48 & -0.22 & -0.03 \\
\hline \multicolumn{7}{|c|}{ After thin-film oven test $($ TFOT) } \\
\hline Penetration at $25^{\circ} \mathrm{C}(0.1 \mathrm{~mm})$ & D5-73 & 32 & 29 & 26 & 25 \\
\hline Softening point ${ }^{\circ} \mathrm{C}$ & $\mathrm{C} 36-76$ & 50 & 60.5 & 64 & 66 \\
\hline
\end{tabular}

\subsection{Mixture design and analysis}

The adopted method for the design of TAO is traditional procedure for the determination of optimum asphalt content (OAC) for wearing course using Marshall Design method. This method was performed as follows:

- Selecting the NMAS: $9.5 \mathrm{~mm}$ NMAS was selected to fulfill the thin asphalt overlay requirements (3 times x 9.5 (NMAS) $=28.5 \mathrm{~mm}<38.1 \mathrm{~mm}$ (the upper limit of TAO thickness).

- Selecting the gradation: dense graded gradations which based on GSRB (9.5 mm NMAS), as mentioned previously, was selected; this gradation is well known in Iraq.

- Determining OAC: five percentages of asphalt content (namely, 4, 4.5, 5, 5.5, and 6, \%) were specified to determine the OAC for the conventional mix with neat asphalt binder. To ensure the reliability, at least three compacted specimens for each percentage were prepared according to ASTM D 6926 [24]. Three types of filler were used (CMF, OPC, and QL), therefore, three OAC were determined accordingly. The OACs for the TAO mixtures with CMF, OPC, and QL fillers were found to be 5.4\%, 5.37\% and 5.3\%, respectively.

In this study, only three parameters where selected from mechanical, volumetric and durability properties to developed statistical models. However, the volumetric properties of TAO mixes with various filler types at OAC are determined; main indexes like bulk density, air void, VFB, and VMA were determined and analyzed according to ASTM D3203 [25] and ASTM D2041 [26], The bulk density (BD) was selected to represent the volumetric properties. The mechanical properties of TAO can evaluated by many tests; e.g., Indirect Tensile strength, Marshall stability and flow, wheel truck test, indirect tensile stiffness, etc. indirect tensile strength (IDT) test according to ASTM D6931 [27] was selected as an important test to represent the mechanical properties of the TAO. Similarly, the durability properties were evaluated by tensile strength ratio (TSR) test according to AASHTO T283[28].

Then, SBS modified polymer binder was introduced for performance enhancement. This polymer was utilized in percentages of $2 \%, 4 \%$ and $6 \%$ of the bitumen content. Volumetric (e.g., bulk density), mechanical (e.g., indirect tensile strength), and durability (tensile strength ratio) testing methods were performed to identify the variations in thin asphalt mixtures characteristics due to such incorporations. The result of bulk density (as an average of three samples results), IDT (as an average of three samples results) and TSR (as an average of three sets results, each set comprised conditioned and unconditioned samples ) are shown in Table

Table 6 Matrix of results

\begin{tabular}{|c|c|c|c|c|}
\hline Filler type & SBS\% & IDT, KPa & TSR, \% & Bulk density, gm/cm $^{3}$ \\
\hline CMF & 0 & 882.6 & 57 & 2.342 \\
\hline CMF & 0 & 956.4 & 56 & 2.34 \\
\hline CMF & 0 & 921 & 58 & 2.338 \\
\hline CMF & 2 & 1714.3 & 65 & 2.368 \\
\hline CMF & 2 & 1783 & 66 & 2.368 \\
\hline CMF & 2 & 1817.2 & 64 & 2.365 \\
\hline
\end{tabular}




\begin{tabular}{|c|c|c|c|c|}
\hline CMF & 4 & 1300 & 68 & 2.365 \\
\hline $\mathrm{CMF}$ & 4 & 1305.6 & 68 & 2.36 \\
\hline CMF & 4 & 1345.1 & 68 & 2.361 \\
\hline CMF & 6 & 1264 & 69 & 2.357 \\
\hline $\mathrm{CMF}$ & 6 & 1296 & 69.5 & 2.359 \\
\hline CMF & 6 & 1290.5 & 68.5 & 2.358 \\
\hline $\mathrm{OPC}$ & 0 & 1142.5 & 76 & 2.345 \\
\hline OPC & 0 & 1170.3 & 81 & 2.344 \\
\hline $\mathrm{OPC}$ & 0 & 1196.3 & 80 & 2.346 \\
\hline $\mathrm{OPC}$ & 2 & 1842 & 86 & 2.388 \\
\hline $\mathrm{OPC}$ & 2 & 1835 & 85 & 2.388 \\
\hline $\mathrm{OPC}$ & 2 & 1852.3 & 87 & 2.385 \\
\hline OPC & 4 & 1398 & 95 & 2.383 \\
\hline OPC & 4 & 1410 & 95 & 2.383 \\
\hline $\mathrm{OPC}$ & 4 & 1397 & 95 & 2.383 \\
\hline OPC & 6 & 1380 & 96 & 2.38 \\
\hline $\mathrm{OPC}$ & 6 & 1371 & 96 & 2.379 \\
\hline OPC & 6 & 1385.4 & 96 & 2.381 \\
\hline QL & 0 & 1294 & 82 & 2.363 \\
\hline QL & 0 & 1261.3 & 82 & 2.363 \\
\hline $\mathrm{QL}$ & 0 & 1283.9 & 82 & 2.363 \\
\hline QL & 2 & 1920 & 85 & 2.384 \\
\hline $\mathrm{QL}$ & 2 & 1896 & 85 & 2.384 \\
\hline $\mathrm{QL}$ & 2 & 1884 & 85 & 2.384 \\
\hline QL & 4 & 1510.4 & 92 & 2.382 \\
\hline $\mathrm{QL}$ & 4 & 1507.3 & 92 & 2.38 \\
\hline $\mathrm{QL}$ & 4 & 1522.5 & 92 & 2.381 \\
\hline $\mathrm{QL}$ & 6 & 1463 & 93 & 2.378 \\
\hline $\mathrm{QL}$ & 6 & 1453.8 & 95 & 2.379 \\
\hline QL & 6 & 1474.6 & 94 & 2.377 \\
\hline
\end{tabular}

\subsection{Statistical Analysis Model}

\subsubsection{Model preparation}

Models preparation from the obtained experiments results are the core work in this study. Empirical modeling was achieved using analysis process offer by SPSS software. Variables involved in the empirical modeling are filler types and percent of SBS. The collected results were 36 for each test of IDT, TSR and $\mathrm{BD}$. The results were divided randomly into 28 results to generate the model and the other 8 were used to validate the developed model. The first step to model preparations is the correlation between the variables by using SPSS Pearson's correlation. Many combinations of variables are used starting from only constant to quadratic form of both variables with the incorporation of multiple terms of both variables discussed above.

\subsubsection{Identification of Variable, coding for empirical modeling and the correlation between variables}

The program used in this study (SPSS) requests to define the independent variables and dependent variables of the developed models to meet the requirements to construct the model. These variables and the code adopted for calculation are listed in Table (7). While, Table (8) shows the bivariate Pearson Correlation between variables, however, this table shows

1. The independent variables have very low to absent of correlation between each other, which is good for the accuracy of the model.

2. The correlation between IDT and filler type is good when compared with polymer content

3. The filler type has the most significant correlation to TSR, then polymer content.

4. The correlation between bulk density and both filler type and polymer content are good, but the correlation with filler type is more significant as explained in Table (8) 
Table 7 Dependent and independent variables considered in regression analysis

\begin{tabular}{|c|c|c|c|}
\hline \multicolumn{5}{|c|}{ Dependent variable } \\
\hline Abbreviation & Description & Unit & Coded values \\
\hline IDT & Indirect tensile strength & $\mathrm{KPa}$ & \\
\hline RD & Wheel track test & $\mathrm{mm}$ & \\
\hline TSR & Water sensitivity & $\%$ & \\
\hline BD & Bulk density & $\mathrm{gm} / \mathrm{cm}^{3}$ & \\
\hline \multicolumn{5}{|}{} \\
\hline F & Independent variable \\
\hline \multicolumn{5}{|c|}{ Filler type } & CMF & 10 \\
& & OPC & \\
\hline P & QL & & 30 \\
\hline
\end{tabular}

Table 8 correlation between variables

\begin{tabular}{|c|c|c|c|c|c|c|}
\hline & & $F$ & $P$ & $I D T$ & $T S R$ & $B D$ \\
\hline \multirow[t]{3}{*}{$F$} & Pearson Correlation & 1 & .000 & .321 & $.761^{* *}$ & $.534^{* *}$ \\
\hline & Sig. (2-tailed) & & 1.000 & .056 & .000 & .001 \\
\hline & $N$ & 36 & 36 & 36 & 36 & 36 \\
\hline \multirow[t]{3}{*}{$P$} & Pearson Correlation & .000 & 1 & .134 & $.420^{*}$ & $.474^{* *}$ \\
\hline & Sig. (2-tailed) & 1.000 & & .437 & .011 & .003 \\
\hline & $N$ & 36 & 36 & 36 & 36 & 36 \\
\hline \multirow[t]{3}{*}{$I D T$} & Pearson Correlation & .321 & .134 & 1 & $.350^{*}$ & $.771^{* *}$ \\
\hline & Sig. (2-tailed) & .056 & .437 & & .037 & .000 \\
\hline & $N$ & 36 & 36 & 36 & 36 & 36 \\
\hline \multirow[t]{3}{*}{$T S R$} & Pearson Correlation & $.761^{* *}$ & $.420^{*}$ & $.350^{*}$ & 1 & $.767^{* *}$ \\
\hline & Sig. (2-tailed) & .000 & .011 & .037 & & .000 \\
\hline & $N$ & 36 & 36 & 36 & 36 & 36 \\
\hline \multirow[t]{3}{*}{$B D$} & Pearson Correlation & $.534^{* *}$ & $.474^{* *}$ & $.771^{* *}$ & $.767^{* *}$ & 1 \\
\hline & Sig. (2-tailed) & .001 & .003 & .000 & .000 & \\
\hline & $N$ & 36 & 36 & 36 & 36 & 36 \\
\hline \multicolumn{7}{|c|}{ **. Correlation is significant at the 0.01 level (2-tailed). } \\
\hline
\end{tabular}

\section{Result and discussion of the prediction model}

SPSS software was used to analysis and build predictive models. For the simplification the linear models were tried first, unfortunately all linear models were failed to represent the observations. For many trails it was found that all models were nonlinear, as will see hereafter.

\subsection{Building the Indirect tensile strength model}

As mentioned previously the IDT was selected to build a model from many mechanical properties. This selection is based on the believe that it is one of the most important parameters, as it represents the cracking phenomenon for the paving materials. Modeling IDT to filler type and polymer content was conducted. Many models were tried (linear, multiple and nonlinear models). It was observed that all linear models were failed to estimate accurate predicted values of IDT. Tables (9) demonstrated samples of the tried models, whereas low values of (R2) are the predominant for both regression and model validation. It is worth mentioned that other testing parameters than $\mathrm{R} 2$ were used to test the validity of the models, but the values of R2 are only presented for simplification and prevent dilatation. 
On the other hand, after many trials a nonlinear model was determined with reasonable accuracy. The analysis results of adopted nonlinear model is presented in Tables $(10,11)$. Table (10) shows the parameter of the developed model and its limitation with Confidence Interval of 95\%. Table (11) demonstrates that the MSE is low and sum of residual is lower that sum of regression which is sustained the significant of the model. Moreover, from the same table, the high value of the R-Square (0. 893) indicates a reasonable prediction, so we can conclude through these values that the developed model for IDT is acceptable. Figure (2) shows the adequacy of model, this figure indicates that acceptable scatter can recognize between predicted and observed IDT values, furthermore, almost all value within the significant level boundaries.

Table 9 trial equations to predict the value of IDT

\begin{tabular}{|c|c|c|}
\hline Types of equations & models & $R^{2}$ \\
\hline Linear & IDT $=10.813+1220.583 * \mathrm{~F}$ & 0.103 \\
\hline Linear & IDT $=1171.215+10.813 * \mathrm{~F}+16.456 * \mathrm{P}$ & 0.121 \\
\hline Cubic & IDT $=1163.208+17.698 * \mathrm{~F}-0.172 * \mathrm{~F}^{2}$ & 0.104 \\
\hline Compound & IDT $=1192.1 * 1.008^{\mathrm{F}}$ & 0.122 \\
\hline Power & IDT $=906.202 * \mathrm{~F}^{0.152}$ & 0.124 \\
\hline Nonlinear & IDT $=1427.938+0.032 * \mathrm{~F}^{*} \mathrm{P}^{2}$ & 0.001 \\
\hline Nonlinear & IDT $=1366.963+1.165 * \mathrm{~F} * \mathrm{P}$ & 0.053 \\
\hline Nonlinear & IDT $=1242.663+12.352 * \mathrm{~F} * \mathrm{P}-1.953 * \mathrm{~F}^{*} \mathrm{P}^{2}$ & 0.472 \\
\hline Nonlinear & IDT $=1199.898-6.511 * \mathrm{~F} * \mathrm{P}+34.4 * \mathrm{~F}^{*} \mathrm{P}^{0.15}$ & 0.697 \\
\hline
\end{tabular}

Table 10 Nonlinear IDT modeling

\begin{tabular}{|l|l|l|l|l|}
\hline Developed model & $I D T=C_{1} * F^{C 2}+C_{3} * P-C_{4} * P^{2}+C_{5} * P^{3}+C_{6}$ \\
\hline \multicolumn{5}{|c|}{ Parameter Estimates } \\
\cline { 3 - 5 } Parameters & Estimate & \multirow{2}{*}{ Std. Error } & \multicolumn{2}{c|}{$95 \%$ Confidence Interval } \\
\cline { 3 - 5 } & & & 8.665 & Upper Bound \\
\hline$C 1$ & 8.665 & .000 & $-409.563-$ & $-85.841-$ \\
\hline$C 2$ & $-247.702-$ & 78.048 & 946.235 & 946.235 \\
\hline$C 3$ & 946.235 & .000 & 262.896 & 436.105 \\
\hline$C 4$ & 349.501 & 41.760 & 25.078 & 41.366 \\
\hline$C 6$ & 33.222 & 3.927 & 1020.387 & 1166.499 \\
\hline
\end{tabular}

Table 11 ANOVA for IDT modeling

\begin{tabular}{|c|c|c|c|}
\hline Source & Sum of Squares & $d f$ & Mean Squares \\
\hline Regression & 60869410.120 & 6 & 10144901.690 \\
\hline Residual & 268556.843 & 22 & 12207.129 \\
\hline Uncorrected Total & 61137966.960 & 28 & 27 \\
\hline Corrected Total & 2521154.147 & Dependent variable: IDT \\
\hline \multicolumn{4}{|c|}{} \\
\hline a. R squared = 1 - (Residual Sum of Squares) / (Corrected Sum of Squares) $=.893$. \\
\hline
\end{tabular}




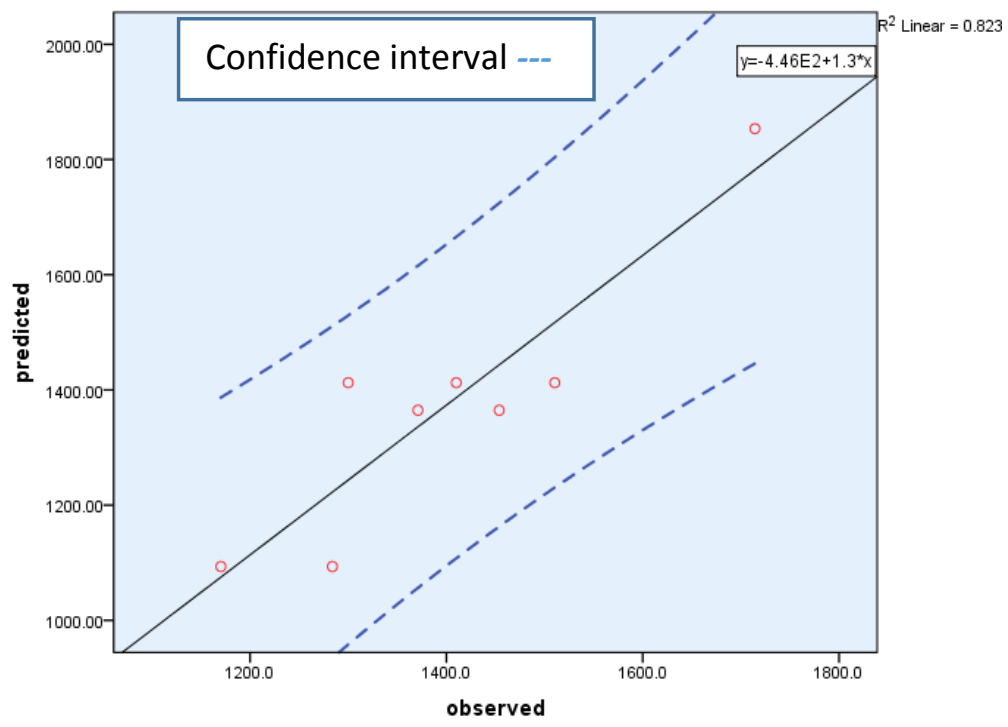

Figure 2 comparisons between the experimental and predicted values of the indirect tensile strength

\subsection{Building the Tensile strength ratio model}

As mentioned previously the TSR was selected to build a model for TAO durability properties. This selection is based on the believe that it is one of the most important parameters beside the aging and abrasion which will initiate by coming research work. Modeling TSR to filler type and polymer content was conducted. Many models were tried (linear, multiple and nonlinear models). It was observed that all linear models were failed to estimate accurate predicted values of TSR. Tables (12) demonstrated samples of the tried models, whereas low values of (R2) are the predominant for both regression and model validation. As mentioned previously in IDT models, that other testing parameters than R2 were used to test the validity of the models, but the values of R2 are only presented for simplification and prevent dilatation. Similarly, after many trials a nonlinear model was determined with reasonable accuracy. The analysis results of adopted nonlinear model is shown in Tables $(13,14)$. Table (14) shows that the MSE is low and sum of residual is lower that sum of regression which mean the significant of the model. From the same table, the high value of the R2 (0.984) indicates a perfect prediction, so we can conclude through these values that the developed model for TSR is acceptable. Figure (3) presents the adequacy of model and indicates that acceptable scatter can recognize between predicted and observed TSR values, furthermore, almost all value within the significant level boundaries.

Table 12 trial equations to predict the value of TSR

\begin{tabular}{|c|c|c|}
\hline Types of equations & models & $R^{2}$ \\
\hline Linear & $\mathrm{TSR}=57.167+1.175 * \mathrm{~F}$ & 0.579 \\
\hline Linear & $\mathrm{TSR}=73.567+2.367 * \mathrm{P}$ & 0.176 \\
\hline Linear & $\mathrm{TSR}=50.067+1.175 * \mathrm{~F}+2.367 * \mathrm{P}$ & 0.755 \\
\hline Logarithmic & $\mathrm{TSR}=14.392+22.855 * \mathrm{LN}(\mathrm{F})$ & 0.676 \\
\hline Inverse & $\mathrm{TSR}=104.077-383.077 / \mathrm{F}$ & 0.741 \\
\hline Power & $\mathrm{TSR}=33.178+\mathrm{F}^{0.302}$ & 0.691 \\
\hline Quadric & $\mathrm{TSR}=15.5+6.175 * \mathrm{~F}-0.125 * \mathrm{~F}^{2}$ & 0.797 \\
\hline Cubic & $\mathrm{TSR}=72.667+2.028 * \mathrm{P}+0.708 * \mathrm{P}^{2}-0.111 * \mathrm{P}^{3}$ & 0.187 \\
\hline Nonlinear & $\mathrm{TSR}=70.951+0.162 * \mathrm{~F}^{*} \mathrm{P}$ & 0.484 \\
\hline Nonlinear & $\mathrm{TSR}=73.567+0.255^{*} \mathrm{~F}^{*} \mathrm{P}-2.74 * \mathrm{P}$ & 0.559 \\
\hline Nonlinear & $\mathrm{TSR}=65.521+0.113 * \mathrm{~F} * \mathrm{P}+0.018 * \mathrm{~F}$ & 0.66 \\
\hline \multicolumn{2}{|c}{} \\
\hline
\end{tabular}


Table 13 Nonlinear TSR modeling

\begin{tabular}{|l|c|c|c|c|}
\hline \multirow{2}{*}{$\begin{array}{l}\text { Developed } \\
\text { model }\end{array}$} & \multirow{2}{*}{ TSR $C_{1}+C_{2} * F-C_{3} * F^{2}+C_{4} * P+C_{5} * P^{2}-C_{6} * P^{3}$} \\
\hline \multicolumn{5}{|c|}{ Parameter Estimates } \\
\hline Parameters & Estimate & Std. Error & \multicolumn{2}{c|}{$95 \%$ Confidence Interval } \\
\cline { 4 - 5 } & & & Lower Bound & Upper Bound \\
\hline$C 1$ & 7.902 & 2.641 & 2.426 & 13.378 \\
\hline$C 2$ & 6.105 & .299 & 5.485 & 6.725 \\
\hline$C 3$ & .123 & .007 & .108 & .139 \\
\hline$C 4$ & 1.815 & 1.299 & $-.879-$ & 4.508 \\
\hline$C 4$ & .853 & .585 & $-.360-$ & 2.065 \\
\hline$C 6$ & .130 & .065 & $-.005-$ & .265 \\
\hline
\end{tabular}

Table 14 ANOVA for TSR modeling

\begin{tabular}{|c|c|c|c|}
\hline Source & Sum of Squares & $d f$ & Mean Squares \\
\hline Regression & 182043.027 & 6 & 30340.504 \\
\hline Residual & 73.473 & 22 & 3.340 \\
\hline Uncorrected Total & 182116.500 & 28 & 27 \\
\hline Corrected Total & 4512.929 & \multicolumn{4}{|c|}{ Dependent variable: TSR } \\
\hline \multicolumn{4}{|c|}{} \\
\hline a. R squared $=1$ - (Residual Sum of Squares) /(Corrected Sum of Squares) $=.984$.
\end{tabular}

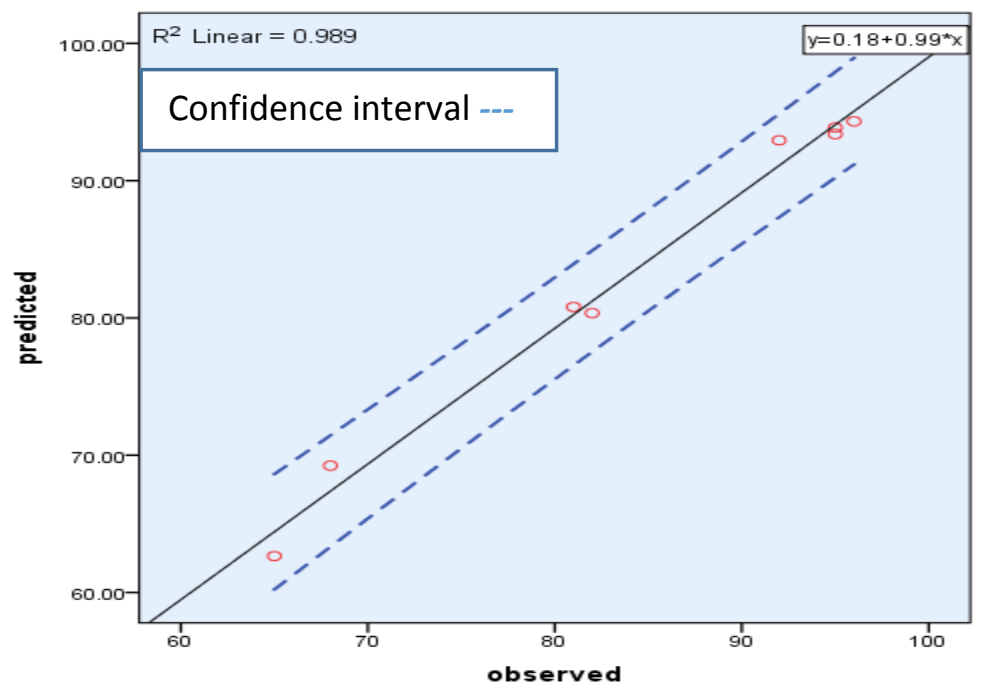

Figure 3 comparisons between the experimental and predicted values of the tensile strength ratio

\subsection{Building the Bulk density model}

As mentioned previously the bulk density was selected to build a model from many others volumetric parameters. This selection is based on the believe that almost volumetric properties showed same trend with significant correlation. Modeling bulk density to filler type and polymer content was conducted. Many models were tried (linear, multiple and nonlinear models). It was observed that all linear models were failed to estimate accurate predicted values of BD. Tables (15) demonstrated samples of the tried models, whereas low values of (R2) are the predominant for both regression and model validation. As mentioned previously in IDT and TSR models, that other testing parameters than R2 were used to test the validity of the models, but the values of R2 are only presented for simplification and prevent dilatation. Similarly, after many trials 
a nonlinear model was determined with reasonable accuracy. The analysis results of adopted nonlinear model are shown in Tables $(16,17)$. The analysis of the models includes the analysis of variance and goodness fitting between observed and predicted values. Figure (4) demonstrates the adequacy of model. The following can be recognized form the analysis process:

- Table (16) shows the parameter of the developed model and its limitation with Confidence Interval of $95 \%$

- Table (17) states that the $\mathrm{MS}_{\mathrm{E}}$ is zero, which is prefrable for the significance of the model

- Table (17) discloses that the sum of regression is higher that sum of residue which is sustained the significant of the model. While, from the same table, the high value of the $\mathrm{R}^{2}(0.973)$ indicates a perfect prediction, thus we can conclude through these values that the developed model for bulk density is acceptable.

- Figure (4) indicates that acceptable scatter can recognize between predicted and observed bulk density values, furthermore, almost all value within the boundaries of $95 \%$ Confidence Interval.

Table 15 trial equations to predict the value of $\mathrm{BD}$

\begin{tabular}{|c|c|c|}
\hline Types of equations & models & $R^{2}$ \\
\hline Linear & $\mathrm{BD}=2.349+0.001 * \mathrm{~F}$ & 0.285 \\
\hline Linear & $\mathrm{BD}=2.359+0.003 * \mathrm{P}$ & 0.225 \\
\hline Linear & $\mathrm{BD}=2.34+0.001 * \mathrm{~F}+0.003 * \mathrm{P}$ & 0.51 \\
\hline Logarithmic & $\mathrm{BD}=2.315+0.019 * \mathrm{LN}(\mathrm{F})$ & 0.315 \\
\hline Inverse & $\mathrm{BD}=2.388-0.306 / \mathrm{F}$ & 0.331 \\
\hline Quadric & $\mathrm{BD}=2.326+0.004 * \mathrm{~F}-0.00007125 * \mathrm{~F}^{2}$ & 0.335 \\
\hline Quadric & $\mathrm{BD}=2.351+0.016 * \mathrm{P}-0.002 * \mathrm{P}^{2}$ & 0.53 \\
\hline Cubic & $\mathrm{BD}=2.349+0.029 * \mathrm{P}-0.009 * \mathrm{P}^{2}+0.001 * \mathrm{P}^{3}$ & 0.596 \\
\hline Nonlinear & $\mathrm{BD}=2.326+0.000125 * \mathrm{~F} * \mathrm{P}+0.003 * \mathrm{~F}-0.0000712 * \mathrm{~F}^{2}$ & 0.521 \\
\hline Nonlinear & $\mathrm{BD}=2.307-0.0000175 * \mathrm{~F} * \mathrm{P}+0.004 * \mathrm{~F}-$ & 0.865 \\
& $0.00007125 * \mathrm{~F}^{2}+0.016 * \mathrm{P}-0.002 * \mathrm{P}^{2}$ & \\
\hline
\end{tabular}

Table 16 Nonlinear BD modeling

\begin{tabular}{|l|c|c|c|c|}
\hline $\begin{array}{l}\text { Developed } \\
\text { model }\end{array}$ & \multirow{2}{*}{$B D=C_{1}+C_{2} * F+C_{3} * F^{2}+C_{4} * P+C_{5} * P^{2}+C_{6} * P^{3}+C_{7} *(P / F)+C_{8} * P^{*} F^{3}$} \\
\hline \multicolumn{5}{|c|}{ Parameter Estimates } \\
\hline Parameters & Estimate & Std. Error & \multicolumn{2}{c|}{$95 \%$ Confidence Interval } \\
\cline { 3 - 5 } & & & 2.314 & Upper Bound \\
\hline$C 1$ & 2.328 & .007 & $-.001-$ & .003 \\
\hline$C 2$ & .001 & .001 & $-4.558 \mathrm{E}-5$ & $4.092 \mathrm{E}-5$ \\
\hline$C 3$ & $-2.333 \mathrm{E}-6$ & .000 & .031 & .043 \\
\hline$C 4$ & .037 & .003 & $-.011-$ & $-.007-$ \\
\hline$C 5$ & $-.009-$ & .001 & .001 & .001 \\
\hline$C 6$ & .001 & .000 & $-.120-$ & $-.045-$ \\
\hline$C 7$ & $-.082-$ & .018 & $-3.244 \mathrm{E}-7$ & $-1.221 \mathrm{E}-7$ \\
\hline$C 8$ & $-2.232 \mathrm{E}-7$ & .000 & & \\
\hline
\end{tabular}

Table 17 ANOVA for BD modeling

\begin{tabular}{|c|c|c|c|}
\hline Source & Sum of Squares & $d f$ & Mean Squares \\
\hline Regression & 157.095 & 8 & 19.637 \\
\hline Residual & .000 & 20 & .000 \\
\hline Uncorrected Total & 157.095 & 28 & \\
\hline Corrected Total & .007 & 27 & \\
\hline \multicolumn{4}{|c|}{ Dependent variable: $B D$} \\
\hline a. $R$ squared $=1-($ & al Sum of Squares) & orrected & quares) $=.973$. \\
\hline
\end{tabular}




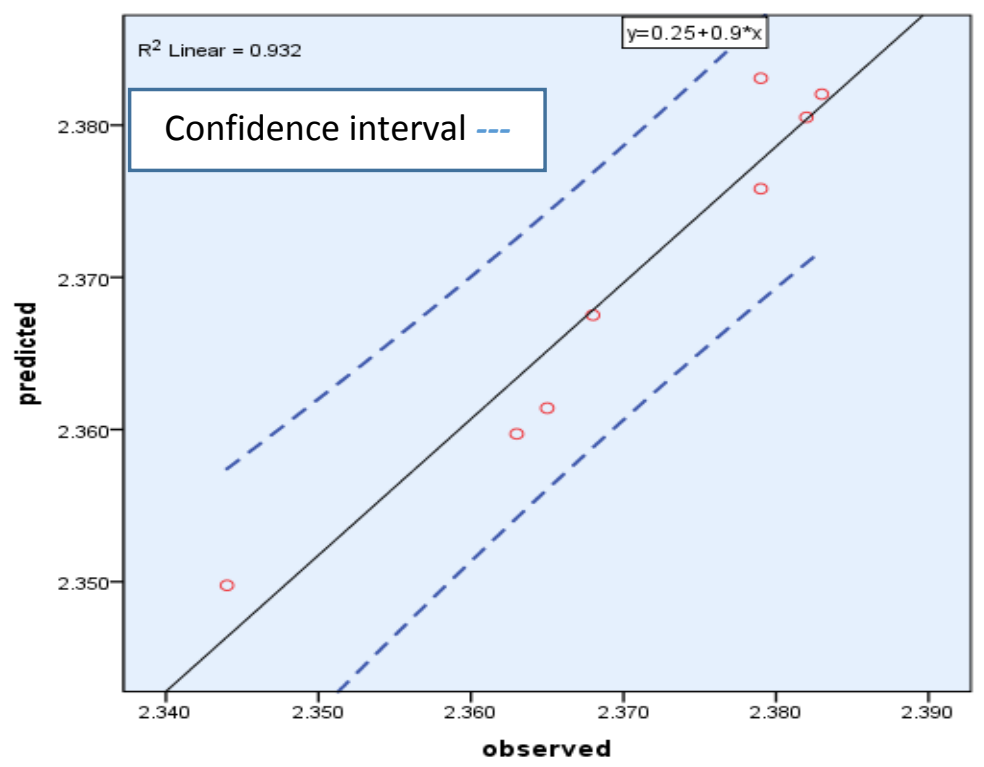

Figure 4 comparisons between the experimental and predicted values of the bulk density

\section{Conclusion}

Within the limitation and the experiment program of this research study, the following can be concluded:

1. General known linear and nonlinear model offered by available software could not represent the resulted values. Where more complicated models are needed

2. The nonlinear equations with some complicated relation are found to be representative to estimate the value of bulk density, IDT and TSR with acceptable reliability, where the results demonstrate that the Mean square of residual for bulk density, IDT and TSR is low and sum of residual is lower that sum of regression which is sustained the significant of the model and the data are close to the fitted regression line which indicates a perfect prediction.

3. Using statistical modeling is achievable and offer a vital tool to describe the characteristics and performance of TAO mixture in term volumetric, mechanical and durability properties. Where these model within the scope of the study proven the significant of the filler type especially for TSR.

\section{CONFLICT OF INTERESTS.}

- There are no conflicts of interest.

\section{References}

[1] J. C. NICHOLLS, I. Carswell, J. T. WILLIAMS, and M. GIBB, "Service lives of thin surfacing systems in the UK," in PROCEEDINGS OF THE 4TH INTERNATIONAL CONFERENCE BITUMINOUS MIXTURES AND PAVEMENTS, HELD THESSALONIKI, GREECE, APRIL 2007-VOLUME1, 2007, no. p25-32.

[2] D. E. Newcomb, “Thin asphalt overlays for pavement preservation,” 2009.

[3] E. Masad, V. K. Jandhyala, N. Dasgupta, N. Somadevan, and N. Shashidhar, "Characterization of air void distribution in asphalt mixes using X-ray computed tomography," J. Mater. Civ. Eng., vol. 14, no. 2, pp. 122-129, 2002.

[4] Y. F. Qiu and K. M. Lum, "Design and performance of stone mastic asphalt," J. Transp. Eng., vol. 132, no. 12, pp. 956-963, 2006.

[5] W. Phislop and B. J. Coree, "VMA as a Design Parameter in Hot-Mix Asphalt [R]," Natl. Coop. Highw. Res. Program, USA, vol. 5, 2002. 
[6] Y. Wang, K. C. Mahboub, and D. E. Hancher, "Survival analysis of fatigue cracking for flexible pavements based on long-term pavement performance data," J. Transp. Eng., vol. 131, no. 8, pp. 608616, 2005.

[7] D. W. Christensen and R. Bonaquist, "Use of strength tests for evaluating the rut resistance of asphalt concrete," J. Assoc. Asph. Paving Technol., vol. 71, 2002.

[8] E. R. Brown, "Density of asphalt concrete: How much is needed?," National Center for Asphalt Technology, 1990.

[9] M. Ameri and A. Behnood, "Laboratory studies to investigate the properties of CIR mixes containing steel slag as a substitute for virgin aggregates," Constr. Build. Mater., vol. 26, no. 1, pp. 475-480, 2012.

[10]S. M. Abtahi, M. Sheikhzadeh, and S. M. Hejazi, "Fiber-reinforced asphalt-concrete-a review," Constr. Build. Mater., vol. 24, no. 6, pp. 871-877, 2010.

[11]M. Arabani, S. M. Mirabdolazimi, and A. R. Sasani, "The effect of waste tire thread mesh on the dynamic behaviour of asphalt mixtures," Constr. Build. Mater., vol. 24, no. 6, pp. 1060-1068, 2010.

[12]D. W. Christensen and R. F. Bonaquist, Evaluation of indirect tensile test (IDT) procedures for lowtemperature performance of hot mix asphalt, no. 530. Transportation Research Board, 2004.

[13]G. Du, Implementation of the SuperPave IDT analysis procedure. 2010.

[14]C. Gorkem and B. Sengoz, "Predicting stripping and moisture induced damage of asphalt concrete prepared with polymer modified bitumen and hydrated lime," Constr. Build. Mater., vol. 23, no. 6, pp. 2227-2236, 2009.

[15]R. P. Lottman, Field Evaluation and Correlation of Laboratory Test Method for Predicting MoistureInduced Damage to Asphalt Concrete. 2001.

[16]I. Padmanaban, S. Kandasamy, and S. C. Natesan, "Statistical modeling of high and low volume of fly ash high compressive strength concrete,” Int. J. Appl. Eng. Res., vol. 4, no. 7, pp. 1161-1167, 2009.

[17]GSRB, “General Specification,” pp. 1-116, 2003.

[18]ASTM, “Test method for penetration of bituminous materials," Dep. Stand. Malaysia, vol. i, pp. 1-5, 2015.

[19]ASTM, "Standard Test Method for Ductility of Bituminous Materials 1,” vol. i, pp. 1-4, 2007.

[20]ASTM, "Standard Test Method for Flash and Fire Points by Cleveland Open Cup Tester," Annu. B. ASTM Stand., vol. i, pp. 1-10, 2005.

[21]ASTM, "Standard test method for softening point of bitumen (ring-and-ball apparatus)," 2015.

[22]ASTM, "Solubility of Asphalt Materials in Trichloroethylene 1,” pp. 1-3, 2015.

[23]D. ASTM, "Standard test method for effects of heat and air on asphaltic materials (thin-film oven test)," Anпи. B. ASTM Stand., vol. 4, 2015.

[24]ASTM, "D6927-15 Standard Test Method for Marshall Stability and Flow of Asphalt Mixtures. Designation: D6927-15,” Am. Soc. Test. Mater., vol. i, pp. 1-7, 2015.

[25]ASTM, "D3203 Standard Test Method for Percent Air Voids in Compacted Dense and Open Bituminous Paving Mixtures," vol. i, no. c, pp. 5-7, 2011.

[26]ASTM, "D2041/D2041M - 11 StandardTheoretical Maximum Specific Gravity and Density of Bituminous Paving Mixtures,” no. January, pp. 8-9, 2015.

[27]ASTM, "Standard test method for indirect tensile (IDT) strength of bituminous mixtures," 2007.

[28]AASHTO, “Determining the creep compliance and strength of HMA.” p. 16, 2003. 


\section{بناء نماذج أداء مختبرية لخطات طبقة الأسفلت السطحية الرقيقة موسى زكي يحيى شاكر فالح شاكر \\ قسم الهندسة المدنية، كلبة الهندسة، جامعة كربلاء، كربلاء، العر|ق \\ shakerfa2003@yahoo.com_mousazekitz@gmail.com}

الخلاصة

تستخدم النمذجة الإحصائية بفعالية لبناء علاقة بين المتغيرات التابعة والمتغيرات المستقلة. وبعبارة أخرى، فهي تصف كيفية ارتباط

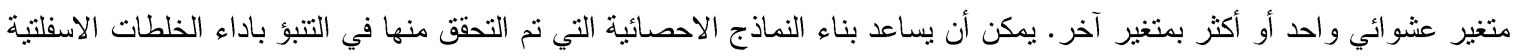
ونوفير الوقت والمال. تهدف هذه الدراسة إلى تقديم نماذج إحصائية تساعد على فهم أهمية المؤشرات المختلفة في تحديد خصائص اداء

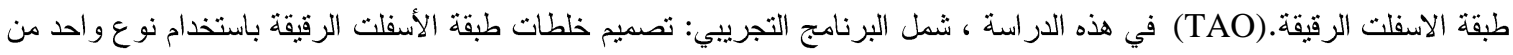

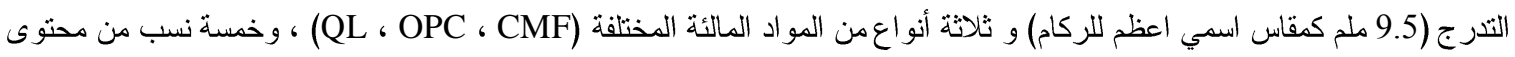
الاسفلت لتحديد محتوى الأسفلت الامتل. ثم بعد ذلك، يتم اضافة مادة البوليمر الستايرين البيوتاديين الستايرين (SBS) لتحسين اداء الخلطة.

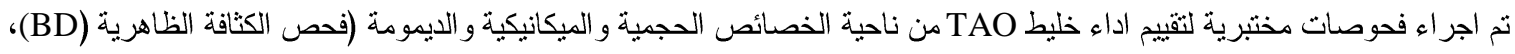

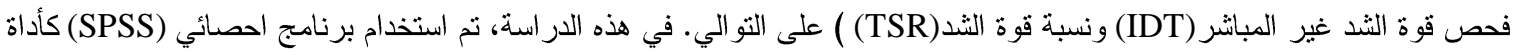

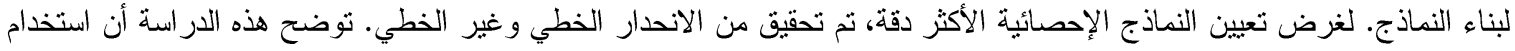

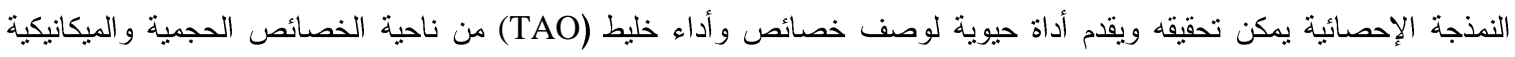
و والديمومة.

الكلمات الدالة: نموذج احصائي، طبقة الاسفلت الرقيقة، الاسفلت المعدل بالبوليمر، قوة الثند الغير مباثرة، الكثافة الظاهرية، نسبة قوة الثند، النورة الحية. 